\title{
Nonlinear hydrodynamics in a Mediterranean lagoon
}

\author{
E. Alekseenko ${ }^{1}$, B. Roux ${ }^{2}$, A. Sukhinov ${ }^{3}$, R. Kotarba ${ }^{2}$, and D. Fougere ${ }^{2}$ \\ ${ }^{1}$ IFREMER, Brest, France \\ ${ }^{2}$ M2P2 UMR 7340 CNRS - Aix-Marseille University and Ecole Centrale Marseille, Marseille, France \\ ${ }^{3}$ Southern Federal University, Taganrog, Russia \\ Correspondence to: E. Alekseenko (lena.alekseenko@gmail.com)
}

Received: 7 August 2012 - Revised: 15 January 2013 - Accepted: 25 January 2013 - Published: 4 March 2013

\begin{abstract}
The paper addresses the application of the nonlinear hydrodynamics model (RANS (Reynolds-averaged Navier-Stokes) equations) in a wide semi-enclosed Mediterranean lagoon (Berre lagoon), considering three natural forcing functions, i.e., sea tide propagating through a long narrow channel, wind and runoff. Main attention is focused to characteristic velocities (at free surface and bottom) and to free surface elevation associated to each of these three mechanisms, with special attention to the nearshore areas (i.e., in shallow water). The most interesting result concerns wind effects which, due to Berre lagoon bathymetry, give rise to downwind coastal jets, alongshore, in shallow water areas. Such coastal jets were never mentioned before in Berre lagoon literature.
\end{abstract}

\section{Introduction}

This paper concerns the hydrodynamics in a lagoonal ecosystem (called Berre lagoon) which was occupied, at the turn of the 20th century, by extensive Zostera noltii meadows (over 6000 ha), which shrinked to about 1.5 ha in 2004 due to environmental impacts of hydroelectric power and other anthropogenic developments as it is reported by Warner (2012). Over the last decades, there have been global declines in seagrass abundance in many places in the world, and management decisions aimed at protecting and restoring submerged aquatic vegetation have been taken in many places (Fonseca et al., 1996; Koch et al., 2006; Pickerell et al., 2005; Van der Heide et al., 2007; Cardoso et al., 2008; Koch et al., 2009, Shafer and Bergstrom, 2010; Vacchi et al., 2012). Of course, it is known that there are a lot of abiotic and biotic factors, which can affect the losses of seagrasses and their lack of recovery. In particular, as kindly pointed out by one reviewer, changes in sediment properties, following the loss of seagrass, is probably an important factor to explain the lack of recovery.

In fact, the problem of the interaction hydrodynamicsmeadows needs a multiscale approach. In our case, the largest scale corresponds to the lagoon size itself $\left(155 \mathrm{~km}^{2}\right)$ : an intermediate would be the beach scale where meadow existed in the past (a few hundred square meters), and finally the meadow scale (a few square meters, for Berre lagoon) would have to be considered. But, the present research is limited to the largest scale, in which we will assume constant coefficients for both surface drag and bottom drag. As reported by Warner (2012), flow dynamics involving changes in water character, circulation and elevation in Berre lagoon, have not been studied in any detail up to now. So, the present paper is aimed to overcome this lack of knowledge and to better understand the impact of three main forcings (semidiurnal tide, wind and freshwater inflow) on the 3-D hydrodynamics in Berre lagoon: the circulation patterns and the bottom current in the nearshore areas (i.e., in shallow water).

\section{Study area}

Berre lagoon is one of the largest Mediterranean brackish lagoons $\left(155 \mathrm{~km}^{2} ; 0.98 \times 10^{9} \mathrm{~m}^{3}\right)$ in the South of France (Fig. 1). Its three main tributaries are situated in the northern part of the lagoon: an EDF (Electricité de France) industrial channel (exit of EDF hydropower station), with a runoff that can reach $250 \mathrm{~m}^{3} \mathrm{~s}^{-1}$ during the peak exploitation period in winter, and two rivers (Arc and Touloubre), with mean runoff equal to $15 \mathrm{~m}^{3} \mathrm{~s}^{-1}$ and $10 \mathrm{~m}^{3} \mathrm{~s}^{-1}$, respectively. Berre lagoon is connected to the Mediterranean Sea through a long and narrow channel, called Caronte. This complex 


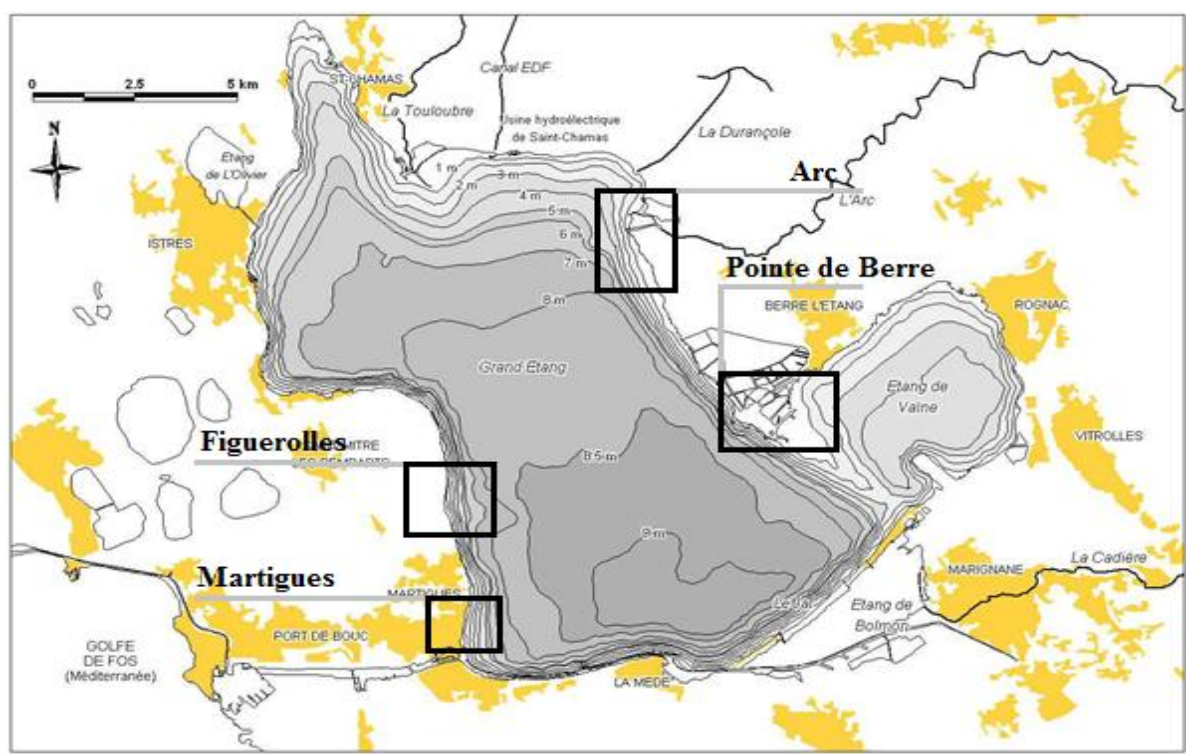

Fig. 1. Berre lagoon and its tributaries (from Bernard et al., 2007).

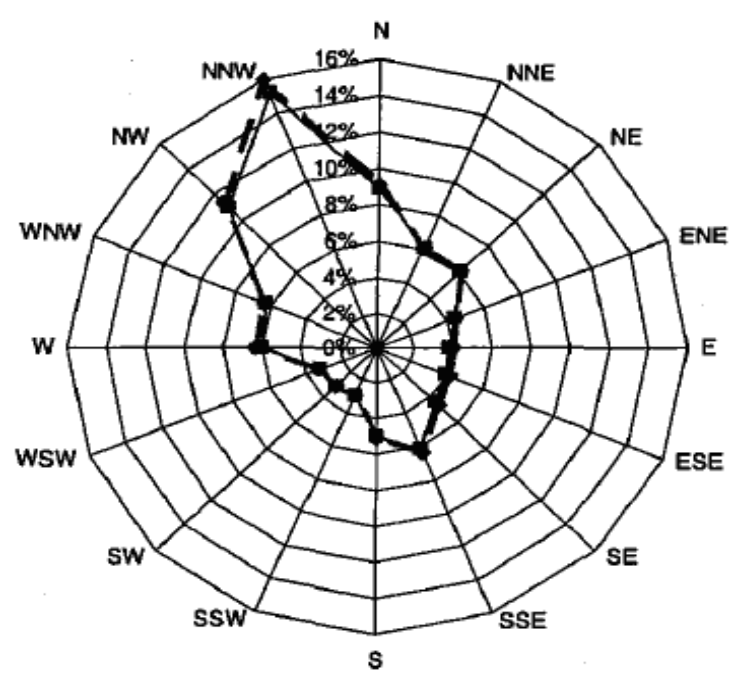

$\longrightarrow-1$ to $21 \mathrm{~m} / \mathrm{s} \longrightarrow 1$ to $11 \mathrm{~m} / \mathrm{s}$

Fig. 2. Distribution of the average wind over $10 \mathrm{~min}$, station of Port de Bouc - $10 \mathrm{~m}$, period 1992-2001 - 24793 observations (Sogreah. 2003).

hydrosystem is subjected to semidiurnal tide, with amplitude up to $30 \mathrm{~cm}$ at the entrance of the channel.

The four control areas of the "Grand Etang" of Berre lagoon, marked by rectangles in Fig. 1, correspond to the places where benthic vegetation existed $50 \mathrm{yr}$ ago and then disappeared completely (Figuerolles and Martigues, on the Western shore) or partially (Arc and "Pointe de Berre", on the Eastern shore).

Concerning the wind, the meteorological data accumulated by Sogreah (2003) for several years (1992-2001) near

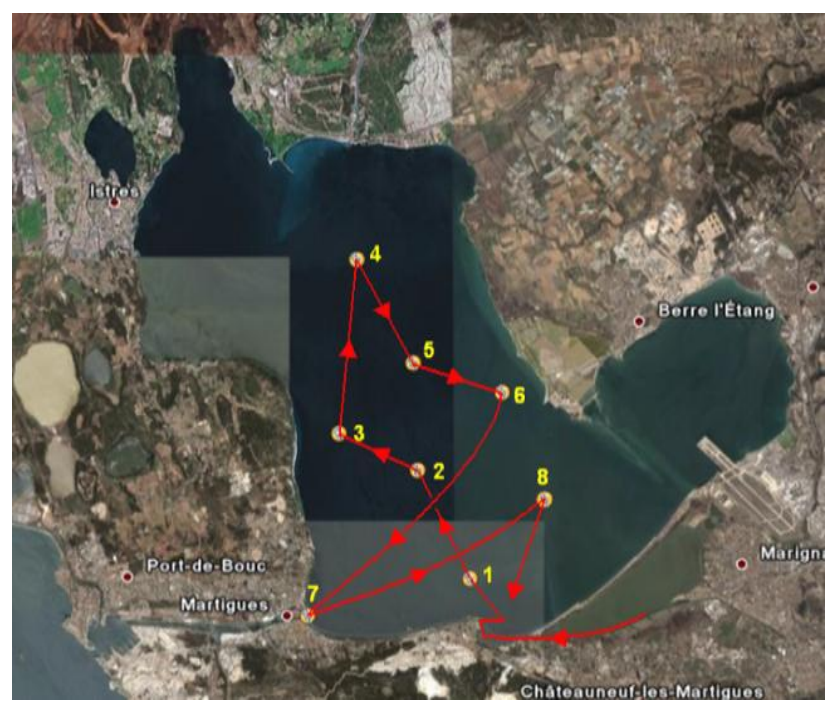

Fig. 3. Places of in situ experiments on 28 September 2006.

Berre lagoon (Port-de-Bouc station) are shown in Fig. 2 with cumulated frequency of winds overpassing $21 \mathrm{~m} \mathrm{~s}^{-1}$ (lozenge symbols) and $11 \mathrm{~ms}^{-1}$ (square symbols), respectively. These data concern average winds (over $10 \mathrm{~min}$ ) at $10 \mathrm{~m}$. Wind speed less than $2 \mathrm{~m} \mathrm{~s}^{-1}$ for all directions represent only $8 \%$ of observations; Berre lagoon is almost permanently windy.

To get a first insight about the global current structure, a few in situ experiments were realized in the "Grand Etang" of Berre lagoon to measure the velocity in the water column, with an acoustic Doppler current profiler (ADCP WHS 
600), on September 2006 at eight relevant places P1-P8 (see, Fig. 3). The results will be discussed here.

\section{Model statement}

The numerical study is realized with MARS3D (3D hydrodynamic Model for Applications at Regional Scale)(Lazure and Dumas, 2008; Fiandrino et al., 2003) following the basic equations proposed by Blumberg and Mellor (1986). The software MARS3D is based on the system of incompressible Navier-Stokes equations in the classical Boussinesq approximation $\left(\rho \sim \rho_{0}\right.$ in momentum equation except for the buoyancy term) with the hydrostatic assumption: $H \ll L$ (Lazure and Dumas, 2008; Blumberg and Mellor, 1986).

Assuming that the free surface elevation is represented by the function $z=\eta(x, y, t)$, and the bottom relief by $z=$ $-H(x, y)$, the model statement of MARS3D in coordinates $(x, y, z)$ is

$\nabla \underline{V}+w_{z}^{\prime}=0$,

$u_{t}^{\prime}+\underline{V} \nabla u+w u_{z}^{\prime}-f v=-\left(1 / \rho_{0}\right) P_{x}^{\prime}+\left(v u_{z}^{\prime}\right)_{z}^{\prime}+F_{x}$,

$v_{t}^{\prime}+\underline{V} \nabla v+w v_{z}^{\prime}+f u=-\left(1 / \rho_{0}\right) P_{y}^{\prime}+\left(v v_{z}^{\prime}\right)_{z}^{\prime}+F_{y}$,

where the pressure, $P$, is obtained by integrating hydrostatic equation $\rho g=-\partial P / \partial z$ from the bottom to the free surface; "prime" is a partial derivative $\left(u_{x}^{\prime} ; u_{y}^{\prime} ; u_{z}^{\prime}\right)=$ $(\partial u / \partial x ; \partial u / \partial y ; \partial u / \partial z)$.

$P(x, y, z, t)=P_{\mathrm{atm}}+\rho_{0} g \eta+g \int_{z}^{0} \rho\left(x, y, z^{\prime}, t\right) d z^{\prime}$,

$\underline{V}$ - velocity vector with horizontal components $(u, v), f-$ Coriolis force, $v$ - coefficient of vertical turbulent exchange, $\rho=\rho(S, T, P)$ - water density, $\rho_{0}$ - reference density, $\mu-$ horizontal eddy viscosity, $F_{x}=\left(2 \mu u_{x}^{\prime}\right)_{x}^{\prime}+\left(\mu\left(u_{y}^{\prime}+v_{x}^{\prime}\right)\right)_{y}^{\prime}$, $F_{y}=\left(2 \mu v_{y}^{\prime}\right)_{y}^{\prime}+\left(\mu\left(u_{y}^{\prime}+v_{x}^{\prime}\right)\right)_{x}^{\prime}$.

The model of MARS3D contains also two equations of thermodynamics for solving salinity and temperature fields:

$T_{t}^{\prime}+\underline{V} \Delta T+w T_{z}^{\prime}=\left(k_{z} T_{z}^{\prime}\right)_{z}^{\prime}+F_{T}$,

$S_{t}^{\prime}+\underline{V} \Delta S+w S_{z}^{\prime}=\left(k_{z} S_{z}^{\prime}\right)_{z}^{\prime}+F_{S}$,

with $F_{T, S}=\left(k_{H}(T, S)_{x}^{\prime}\right)_{x}^{\prime}+\left(k_{H}(T, S)_{y}^{\prime}\right)_{y}^{\prime}$, where $k_{H}, k_{z}-$ coefficients of horizontal and vertical diffusion.
The boundary conditions on the free surface $z=\eta(x, y)$ are

$\rho_{0} v\left(u_{z}^{\prime}, v_{z}^{\prime}\right)=$

$\left(\tau_{0 x}, \tau_{0 y}\right), w=u \eta_{x}^{\prime}+v \eta_{y}^{\prime}$

$+\eta_{t}^{\prime}, \rho_{0} k_{z}(T, S)=\left(Q_{T} / C_{p}, 0\right)$

where $\left(\tau_{0 \mathrm{x}}, \tau_{0 y}\right)-$ horizontal components the vector of the wind stress on the free surface, $C_{p}-$ constant, $Q_{T}$ - heat flux at the air-sea interface.

On the lower boundary; i.e., for $z=-H(x, y)$, we assume that

$\rho_{0} v\left(u_{z}^{\prime}, v_{z}^{\prime}\right)=\left(\tau_{b x}, \tau_{b y}\right), w_{b}=$

$-u_{b} u_{x}^{\prime}-v_{b} v_{y}^{\prime}, \rho_{0} k_{z}(T, S)=(0,0)$,

where $\left(\tau_{b x}, \tau_{b y}\right)$ - horizontal components vector of the tension stress on the bottom.

$\left(\tau_{0 x}, \tau_{0 y}\right)=\rho_{a} C d_{s}\|\boldsymbol{W}\|\left(W_{x}, W_{y}\right)$, where $W$ - wind velocity, $C d_{s}=0.0016-$ surface drag coefficient, $\rho_{a}$ - atmospheric density.

$\left(\tau_{b x}, \tau_{b y}\right)=\rho_{0} C d_{B}\|\underline{V}\|(u, v), \quad$ where $\quad C d_{B}=$ $\left(k / \ln \left(\left(z+H+z_{0}\right) / z_{0}\right)\right)^{2}$ - bottom drag coefficient with $k=0.4-$ Von Karman constant, $z_{0}$ - bottom roughness (in our model $z_{0}=0.0035 \mathrm{~m}$ ).

For the turbulence closure, the Prandtl model (Wilcox, 2004) was chosen to represent the vertical turbulent exchange coefficient.

\section{Numerical modeling and mesh strategy}

In MARS3D software, the water column is divided into layers in the transformed vertical "sigma" grid adapted to the bottom and free surface shapes: $\sigma=(z-\eta) /(H+\eta)$; varying from -1 at the bottom $-H$, to 0 at the free surface $\eta$. For the discretization of Eqs. (1) - (6) different grids are tested. A uniform grid for the horizontal axes and a nonuniform grid for the vertical axis are implemented as follows

$w_{h}=\left\{x_{i}=i h_{x}, y_{j}=j h_{y}, \sigma_{k}=k h_{\sigma} ; i=\overline{1 . . N_{x}}, j=\right.$ $\left.\overline{1 . . N_{y}}, k=\overline{1 . . N_{\sigma}} ; N_{x} h_{x}=L_{x}, N_{y} h_{y}=L_{y}, \quad N_{\sigma} h_{\sigma}=1\right\}$, where $i, j, k$ - indexes for directions $x, y, z ; h_{x}, h_{y}, h_{\sigma}$ - spatial steps; $N_{x}, N_{y}, N_{\sigma}$ - number of nodes along the two horizontal coordinate directions $L_{x}, L_{y}$, and along "sigma" direction, respectively. Concerning the horizontal directions, most of the numerical simulations are performed for $h_{x}=h_{y}=50 \mathrm{~m}, N_{x}=376, N_{y}=355$.

As a first variant of the vertical grid, the water column is simply divided into $N_{\sigma}-1$ internal layers of nondimensional thickness $h_{\sigma}$, and two limiting layers: BL (Bottom layer) and FSL (Free Surface Layer), of nondimensional thickness $0.5 h_{\sigma}$. The relationship between the thickness of the two limiting layers $\Delta \varepsilon_{H}=0.5 H h_{\sigma}$ and the number of node $N_{\sigma}$ is simply given as a function of the depth $H$ in the water basin. For example, for the maximum depth $(H=9 \mathrm{~m})$ the 


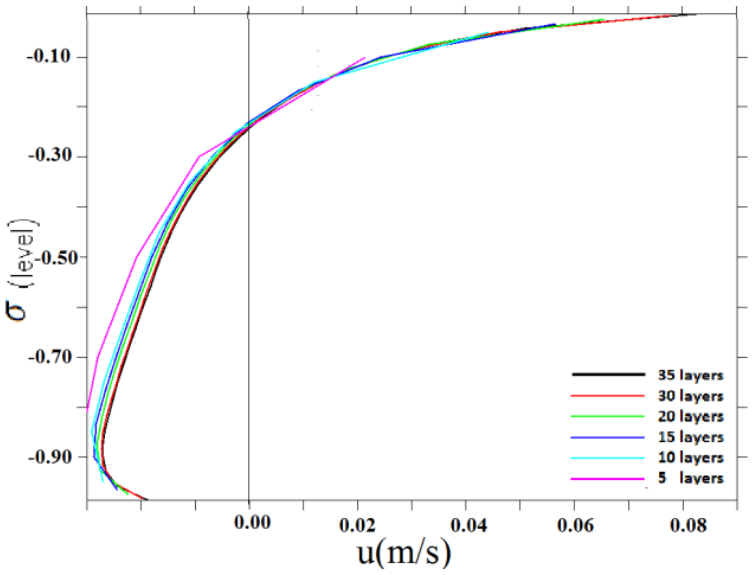

(a)

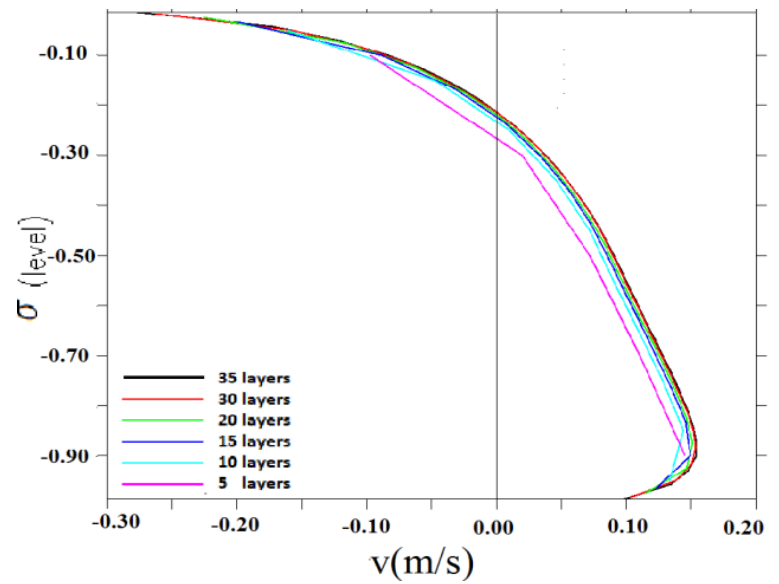

(b)

Fig. 4. Profiles of horizontal velocity components $\underline{V}$ : (a) $u$ and (b) $v$ for different numbers of layers $N_{\sigma}$ at point 1 in Fig. 3 , for $H=9 \mathrm{~m}$ in the case of NNW wind of $80 \mathrm{~km} \mathrm{~h}^{-1}, 24 \mathrm{~h}$ after the beginning of simulation.

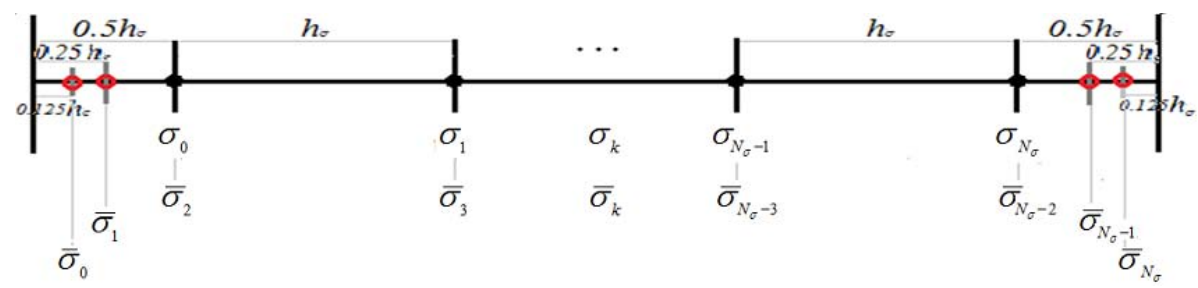

Fig. 5. Refinement schema for the vertical direction in the two limiting layers BL and FSL; red points - additional nodes in the two limiting layers.

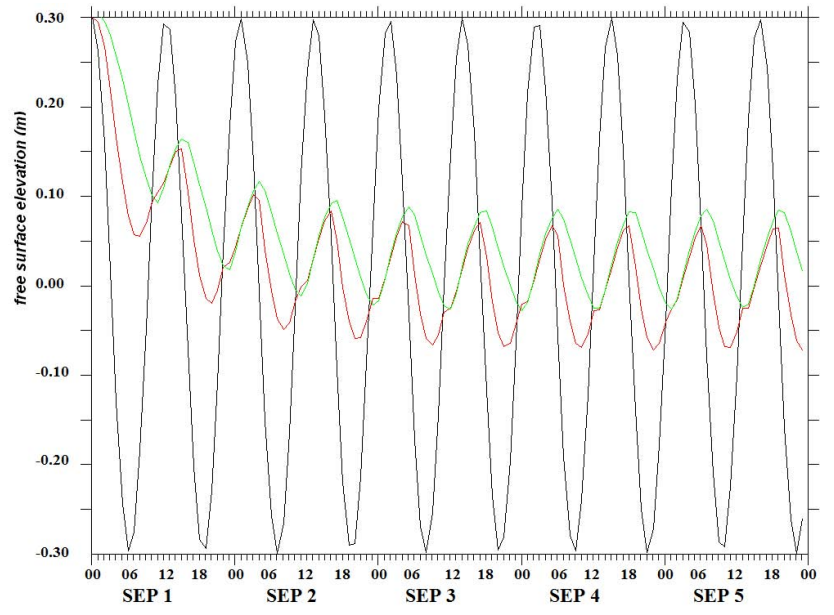

Fig. 6. Time evolution of the free surface elevation at three characteristic points: entrance of Caronte channel (sea level) - first line in black ; inside the Berre lagoon at the exit of Caronte channel second line in red ; inside the Berre lagoon at the point 8 of Fig. $4-$ third line in green). step size used for the discretization with $N_{\sigma}=20$, is $0.225 \mathrm{~m}$ in both limiting layers.

Figure 4 shows the grid effect on the computed horizontal velocity components $\underline{V}=(u, v)$ in the water column, in the case of a flow driven by the wind only (oriented NNW, with a speed of $80 \mathrm{~km} \mathrm{~h}^{-1}$ ). The component $u$ is positive in the sense of $x$ increasing (from east to west), while the component $v$ is positive in the sense of y increasing (from south to north). The results are given at a selected control place (point 1, in Fig. 3), where $H=9 \mathrm{~m}$.

As a second grid variant, we implemented a refinement in both limiting layers, as indicated in Fig. 5 , in such a way that the nondimensional thickness of the two limiting layers is reduced by a factor 4 , from $0.5 h_{\sigma}$ to $0.125 h_{\sigma}$. In this variant, the number of vertical nodes is increased by $4: \bar{N}_{\sigma}=N_{\sigma}+4$.

To test simulation accuracy, computations are performed for $\bar{N}_{\sigma}=24$ (i.e., for $N_{\sigma}=20$ and $h_{\sigma}=1 / 20$ ), for which the thickness of the two limiting layers is reduced to $5.625 \mathrm{~cm}$ at the most profound place (i.e., for $H=9 \mathrm{~m}$ ). We concluded that this second grid variant, with $\bar{N}_{\sigma}=24$, provides sufficient accuracy, and we decided to perform the present study with such a grid. 


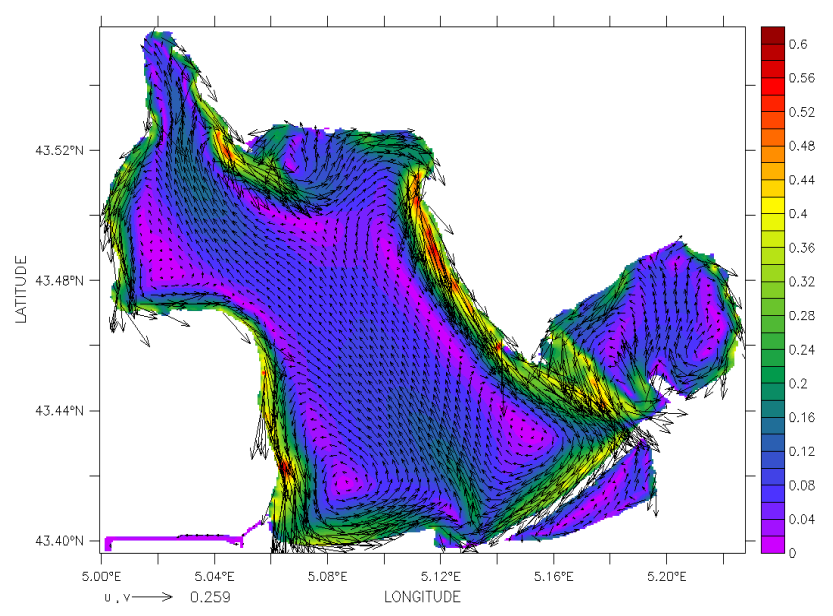

Fig. 7. Barotropic currents and velocity modulus for NNW wind of $80 \mathrm{~km} \mathrm{~h}^{-1}$.

\section{Main dynamical forcing mechanisms in Berre lagoon}

In this paragraph, we perform a more detailed analysis of the effect of the three main dynamical forcings in Berre lagoon, i.e.: wind, tide, and freshwater inflow (runoffs). The following model conditions are considered:

- sinusoidal tide (salt water inflow through a long and narrow channel, called Caronte, connecting the Mediterranean Sea to Berre lagoon), with amplitude up to $30 \mathrm{~cm}$ at the entrance of the channel;

- constant wind velocity, for the two main orientations (NNW and SSE), ranging from $18 \mathrm{~km} \mathrm{~h}^{-1}$ to $100 \mathrm{~km} \mathrm{~h}^{-1}$, according to the wind rose (Fig. 2).

- constant runoffs: (a) from EDF hydropower station, ranging from $50-200 \mathrm{~m}^{3} \mathrm{~s}^{-1}$, and (b) from two rivers (Arc and Touloubre), equal to $15 \mathrm{~m}^{3} \mathrm{~s}^{-1}$ and $10 \mathrm{~m}^{3} \mathrm{~s}^{-1}$, respectively.

We first analyze the impact of each forcing, separately, on the overall pattern of currents, and in the nearshore zones (typically $500 \mathrm{~m} \times 500 \mathrm{~m}$ ); in particular, the eastern nearshore zone called "Pointe de Berre" (shown in Fig. 1).

In all cases, the initial condition used for the numerical simulation is the quiescent state (zero velocity everywhere) at $t=0$. For each set of meteorological conditions, it takes about two or three days for the numerical simulation to converge to a stable state, starting from the quiescent state.

Although our numerical simulation provides 3-D currents, only a few hydrodynamical characteristics: surface current, mean bottom current and barotropic currents (average along the vertical) will be shown and discussed in the present paper.

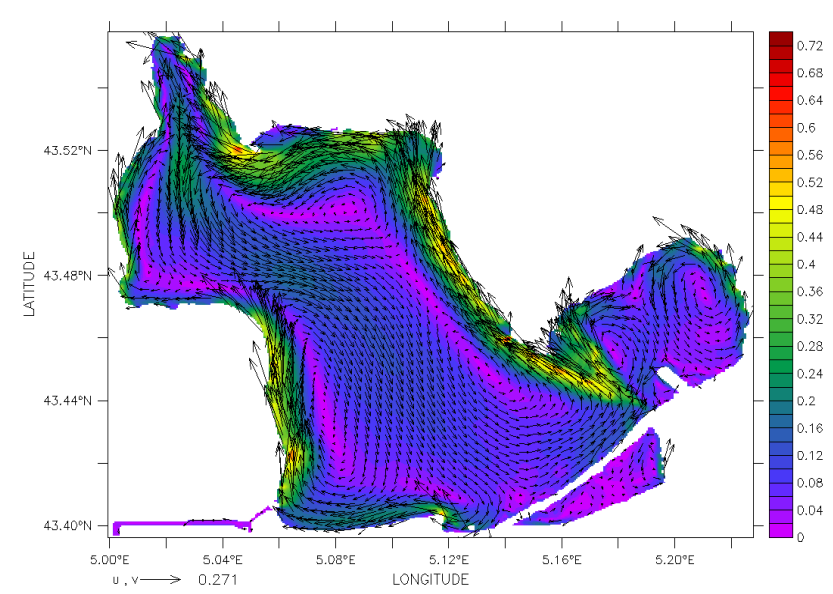

Fig. 8. Barotropic currents and velocity modulus for SSE wind of $80 \mathrm{~km} \mathrm{~h}^{-1}$.

\subsection{Tidal effects in the Berre lagoon}

The Caronte channel by which the Mediterranean salty water penetrates into the lagoon is narrow (100-250 $\mathrm{m}$ wide) and long $(6.5 \mathrm{~km})$. To analyze how the tide propagates along the channel and inside the lagoon; we assume a scenario without wind and without EDF runoff. The semidiurnal sea tide is represented by a harmonic law for the free surface elevation at the open boundary of the Caronte channel: $\eta(t)=$ $0.3 \cos (2 \pi(t-t 0) / T)$, where $t 0$ - beginning time of computation, $T$ - tidal period (about $44712 \mathrm{~s}$ or $12 \mathrm{~h} 25 \mathrm{~min}$ ). The tidal amplitude of $0.3 \mathrm{~m}$ was chosen according to local tidegauge measurements in the Gulf of Fos at the entrance of the Caronte channel.

To establish the harmonic behavior of the tidal effect in the whole lagoon, several tens of hours of numerical simulation starting from a quiescent state were necessary. The time evolution of the free surface elevation is presented in Fig. 6 for three characteristic points: (a) entrance of the Caronte channel (sea level), (b) exit of the Caronte channel into Berre lagoon, and (c) inside the Berre lagoon at the point 8 of Fig. 3 (close to the nearshore area of Pointe de Berre, ZB). The tide amplitude reaches about $7 \mathrm{~cm}$ at the exit of Caronte channel (red line) and about $6 \mathrm{~cm}$ near ZB (green line); that means that the tide inside decreases up to 5 times compared with the sea tide amplitude of $30 \mathrm{~cm}$. We also observe a phase shifting - a time delay of tide propagation (free surface elevation maximum): inside the Berre lagoon of about $3 \mathrm{~h}$ at the exit of the Caronte channel (red line) and of about $4 \mathrm{~h}$ near the nearshore zone ZB (green line).

The present numerical results are well coherent with tidegauge observations reported by Ramade (1997) with tide amplitude decreasing up to 4-6 times, and a phase shifting of about $4 \mathrm{~h}$.

In most part of the "Pointe de Berre" area, the velocity module is small enough $\left(0-5 \mathrm{~cm} \mathrm{~s}^{-1}\right.$ for the barotropic 
(a)
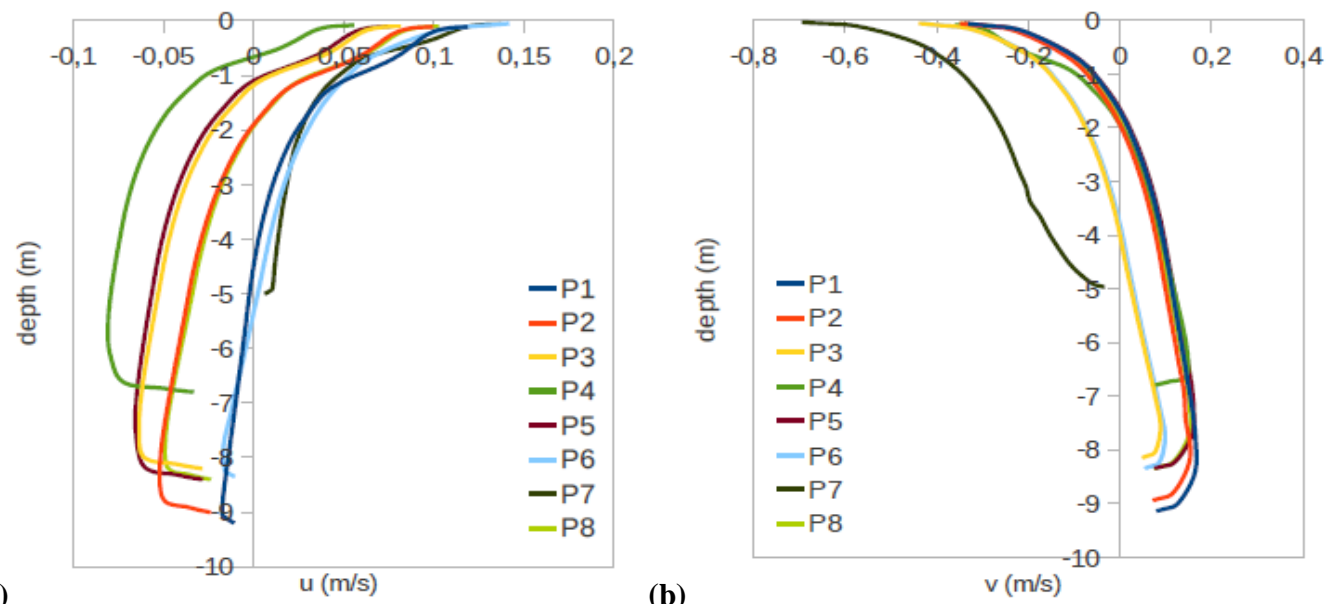

(b)

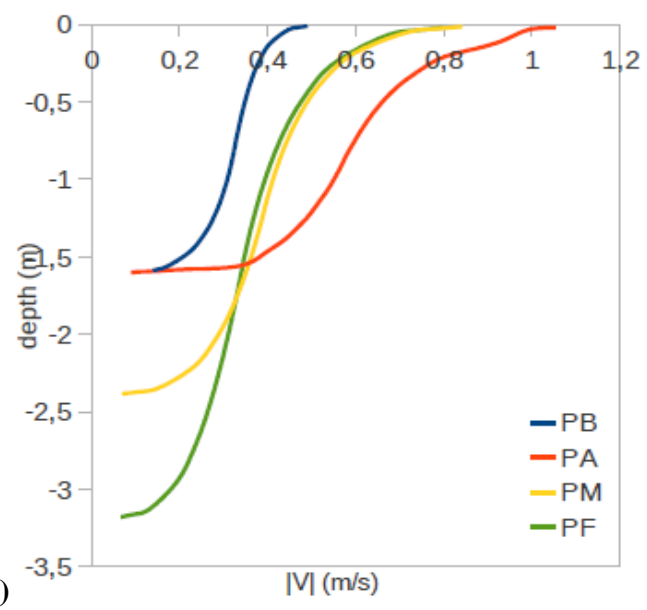

Fig. 9. Vertical velocity profile for NNW wind of $80 \mathrm{~km} \mathrm{~h}^{-1} ; u, v$ components for the 8 control points inside "Grand Etang" (a, b), and (c) velocity modulus at the 4 nearshore control points PA, PB, PM and PF.

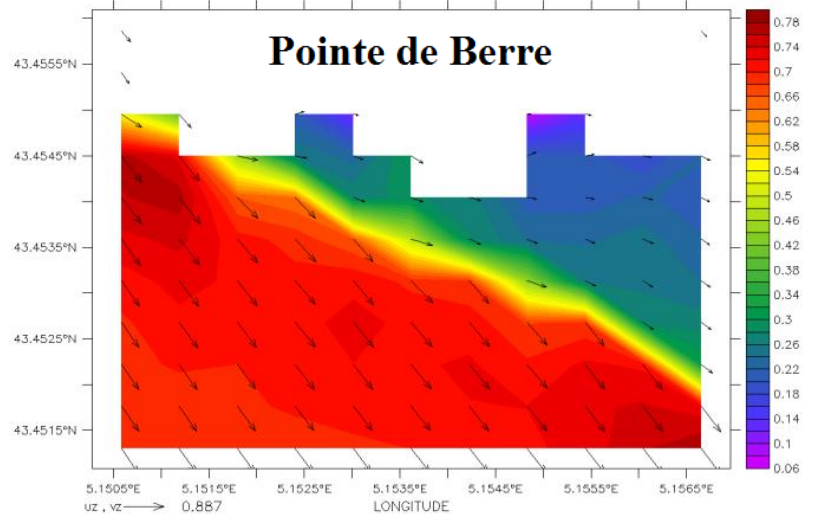

(a)

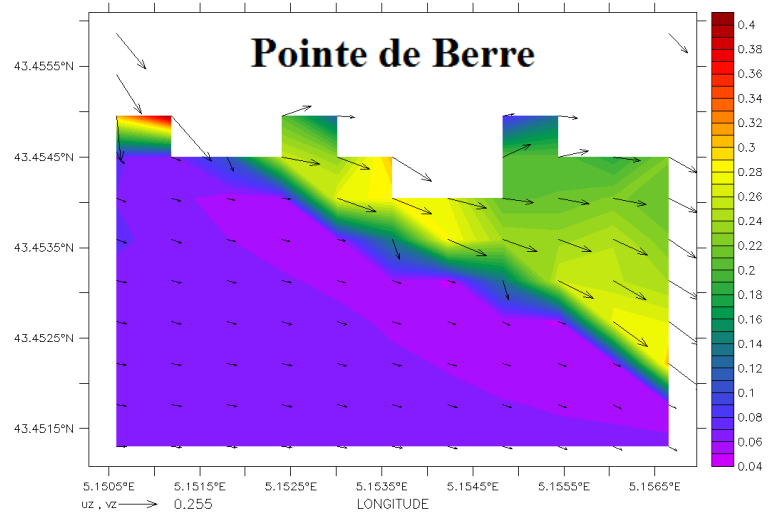

(b)

Fig. 10. Nearshore currents; (a) free surface, (b) bottom; in the square domain ZB, for a NNW wind of $80 \mathrm{~km} \mathrm{~h}-1$. 
regime), in comparison with the currents inside the Caronte channel (1-2 $\mathrm{m} \mathrm{s}^{-1}$ during the reflux and flux, respectively).

\subsection{Wind effect in Berre lagoon}

Due to the shallowness, currents and hydrodynamics of Berre lagoon are closely conditioned by the bottom topography, and wind affects the entire water column, as for many other Mediterranean lagoons (Perez-Ruzafa, 2011). Wind stress, which is caused by moving atmospheric disturbance, is known to have a major influence in lagoon water circulation. Because the scale of the lagoon body is small in comparison with the scale of cyclonic disturbances, the geostropic wind will be assumed to be uniform in the present numerical study; speed values of $80 \mathrm{~km} \mathrm{~h}^{-1}$ for each of the two main directions NNW and SSE will be considered; barotropic currents are shown in Figs. 7 and 8, respectively.

It is observed that the (vertically integrated) barotropic current is maximal alongshore in the wind direction; it presents two principal gyres, longed downwind, which divide the "Grand Etang" in two parts, with opposite current to the wind direction in the deeper central part and two codirectional currents, stronger, along the eastern and western shores.

For a SSE wind of $80 \mathrm{~km} \mathrm{~h}^{-1}$, Fig. 8 shows strong downwind currents along the eastern and western shores. Analogically to the NNW wind (Fig. 13), there are two main gyres, but circulating in the opposite sense.

Barotropic current fields, in Figs. 7-8, give a global (vertically integrated) information about current structure in the whole lagoon, but cannot reflect complexity of the velocity distribution in the vertical direction. As an example of such complexity, we present in Fig. 9a, b, at the 8 control points (P1-P8) shown in Fig. 3, the vertical profiles of the two horizontal components of the velocity; the component $u$ being positive in the sense of $x$ increasing (from east to west), while the component $v$ is positive in the sense of y increasing (from south to north). A change of the current direction is observed at a depth of about 1-2 $\mathrm{m}$ at the points $1,2,4,5$ and 8 (i.e., more inside), and of about $3-4 \mathrm{~m}$ at the points 3 and 6 (closer to shore). Point 7 is special, with a larger velocity; it corresponds to the zone of water exchange between Berre lagoon and the Caronte channel.

Figure 9c shows the profiles of the velocity modulus for 4 nearshore control points PB, PA, PM and PF. In the bottom layer, we determined an averaged velocity modulus (mean value at the three vertical mesh points in the limiting bottom layer (i.e., at $h=H / 40$ from the bottom). Strong enough bottom currents exist at the center of these four nearshore control zones: $13.7 \mathrm{~cm} \mathrm{~s}^{-1}$ at $\mathrm{PB}, 16.2 \mathrm{~cm} \mathrm{~s}^{-1}$ at PA, $11.2 \mathrm{~cm} \mathrm{~s}^{-1}$ at PM and $10 \mathrm{~cm} \mathrm{~s}^{-1}$ at PF. Due to these high enough bottom velocities, which correspond to strong enough shear stress, we can expect an impact on the sediment composition, and so, on the erosion resistance of the sediment (Ahmad et al., 2011). Indeed, the living Zostera noltii are generally growing

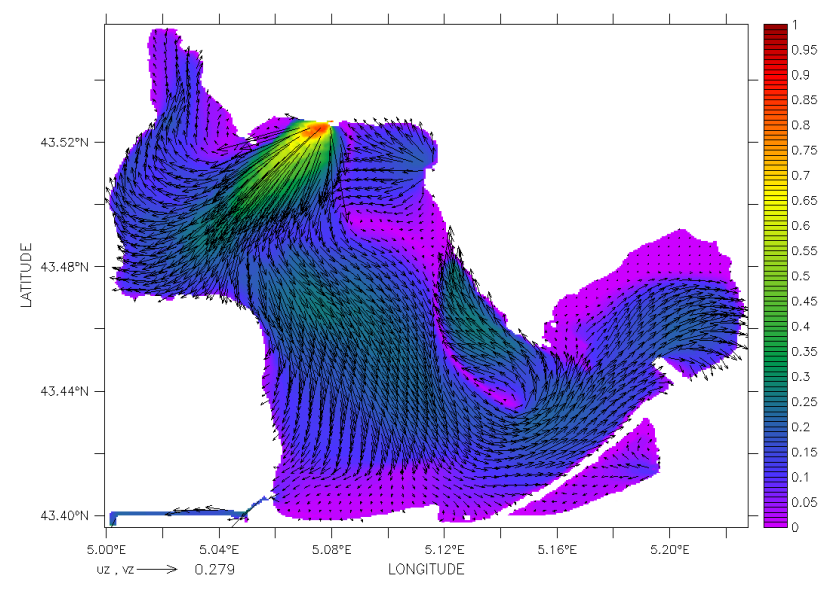

Fig. 11. Currents near the free surface and velocity modulus for EDF runoff of $125 \mathrm{~m}^{3} \mathrm{~s}^{-1}$.

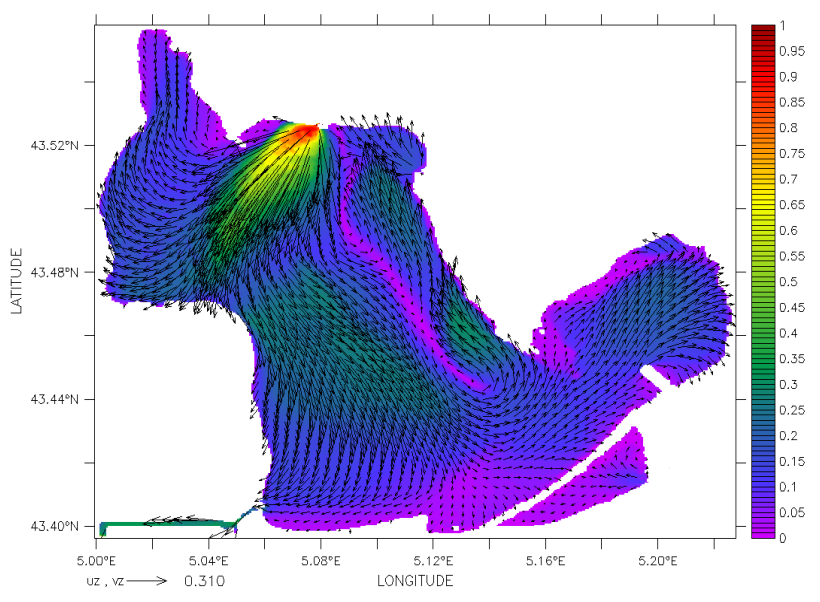

Fig. 12. Currents near the free surface and velocity modulus for EDF runoff of $200 \mathrm{~m}^{3} \mathrm{~s}^{-1}$.

on mud-sand sediments; but when these plants disappeared in the past, due to fresh water stressor, the sediment composition was probably changed by a decreasing of mud concentration.

More detailed results of nearshore velocity fields at the free surface and at the bottom are given, as an example, in a square domain ZB (Pointe de Berre) of dimension $500 \mathrm{~m} \times 500 \mathrm{~m}$ around the control point PB. The velocity fields for a NNW wind of $80 \mathrm{~km} \mathrm{~h}^{-1}$ are given in Fig. 10a for the free surface and in Fig. 10b for the sea bed. We can observe that starting from the control point PB (at the centre of $\mathrm{ZB}$ area) in direction of the shore, the free surface velocity diminishes monotonically when approaching the shoreline; but on the contrary, the bottom velocity reaches values substantially higher (Fig. 10b) in some parts of the shallow water. Typically, the bottom speed can be of the order of $0.2 \mathrm{~m} \mathrm{~s}^{-1}$ at PB (situated at $250 \mathrm{~m}$ from the shore), but becomes twice as fast at about $100 \mathrm{~m}$ of the shore. This observation is in 


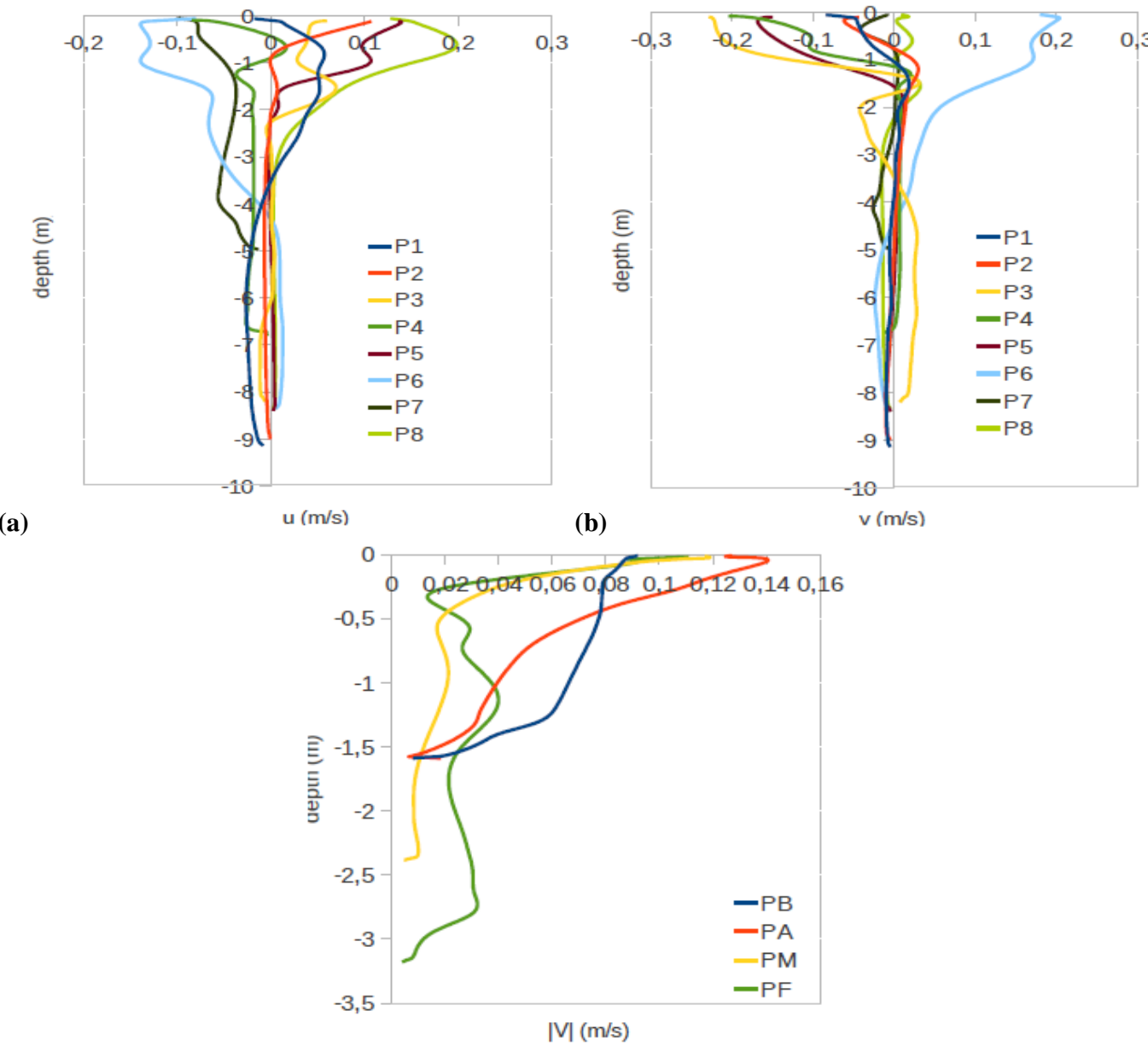

(c)

Fig. 13. Vertical velocity profile for EDF runoff of $200 \mathrm{~m}^{3} \mathrm{~s}^{-1} ; u, v$ components for the 8 control points inside "Grand Etang" (a, b), and (c) velocity modulus at the 4 nearshore control points PA, PB, PM and PF.

agreement with the remark of Wiseman and Rouse (1980) about the importance of interaction with the topography (shallow bathymetry) mentionned by Allen (1975), in addition to the barotropic nature of the flow pointed out by Csanady (1971).

\subsection{Influence of large freshwater runoffs}

In this subchapter, the influence of large freshwater runoffs in the northern part of "Grand Etang" is analyzed in the case without wind or tidal effects. Two different values of EDF runoffs: $125 \mathrm{~m}^{3} \mathrm{~s}^{-1}$ and $200 \mathrm{~m}^{3} \mathrm{~s}^{-1}$ are considered. Additional inflows of the two rivers "Arc" and "Touloubre" (see Fig. 1), are also taken into account $\left(15 \mathrm{~m}^{3} \mathrm{~s}^{-1}\right.$ and $10 \mathrm{~m}^{3} \mathrm{~s}^{-1}$, respectively). To analyze the impact of the EDF runoffs, we first consider the structure and intensity of the currents at the free surface layer for two selected runoffs (Figs. 11 and 12, respectively).

The flow coming from the EDF hydropower station is deflected by the western shore and divided in two branches; then the southern branch impinges the southern shore and is mainly deflected to the eastern direction. The contribution of river runoffs (Arc and Touloubre) is also visible.

In Figs. 11 and 12, the global structure of the currents in the "Grand Etang" is the same, with two branches deflected by the western shore, but with stronger currents. In these cases, the deflection of the southern branch by the southern shore is stronger and gives rise to a counterclockwise gyre, with a significant returning current flowing along the eastern shore.

As in the previous subchapter, it is interesting to consider the vertical velocity profiles at some relevant places (8 control points in "Grand Etang", and 4 nearshore control points). Figure 13 permits us to understand that the EDF runoff affects mainly the current near the free surface, for most of the control points in the central part of the Berre lagoon ( $3 \mathrm{~m}$ under the free surface) and the nearshore control points $(1 \mathrm{~m}$ under the free surface). The surface velocity does not exceed $25 \mathrm{~cm} \mathrm{~s}^{-1}$. At the points P1, P3 and P5 we can see a 
Table 1. Characteristic velocities, $|\mathrm{V}|$ surface, $|\mathrm{V}|$ bottom and $|\mathrm{V}|$ mean, at the four nearshore control points for different forcings.

\begin{tabular}{|c|c|c|c|c|c|}
\hline$|\mathrm{V}|$ & Tide & $\begin{array}{l}\text { EDF } \\
200 \mathrm{~m}^{3} \mathrm{~s}^{-1}\end{array}$ & $\begin{array}{l}\mathrm{NNW} \\
80 \mathrm{~km} \mathrm{~h}^{-1}\end{array}$ & $\begin{array}{l}\mathrm{SSE} \\
80 \mathrm{~km} \mathrm{~h}^{-1}\end{array}$ & $\begin{array}{l}\text { SSE } 80 \mathrm{~km} \mathrm{~h}^{-1} \\
+ \text { EDF } 200 \mathrm{~m}^{3} \mathrm{~s}^{-1}\end{array}$ \\
\hline \multicolumn{6}{|c|}{$\mathrm{PB}$} \\
\hline$|\mathrm{V}|$ surface & 0.0806 & 0.090 & 0.490 & 0.662 & 0.663 \\
\hline$|\mathrm{V}|$ bottom & 0.0026 & 0.0147 & 0.155 & 0.190 & 0.191 \\
\hline$|\mathrm{V}|$ mean & 0.0229 & 0.0635 & 0.318 & 0.401 & 0.402 \\
\hline \multicolumn{6}{|c|}{ PA } \\
\hline$|\mathrm{V}|$ surface & 0.071 & 0.127 & 1.054 & 1.017 & 1.010 \\
\hline$|\mathrm{V}|$ bottom & 0.008 & 0.007 & 0.158 & 0.1646 & 0.163 \\
\hline$|\mathrm{V}|$ mean & 0.024 & 0.0615 & 0.573 & 0.5601 & 0.556 \\
\hline \multicolumn{6}{|c|}{ PM } \\
\hline$|\mathrm{V}|$ surface & 0.228 & 0.117 & 0.841 & 0.844 & 0.839 \\
\hline$|\mathrm{V}|$ bottom & 0.038 & 0.007 & 0.114 & 0.137 & 0.139 \\
\hline$|\mathrm{V}|$ mean & 0.136 & 0.028 & 0.410 & 0.449 & 0.449 \\
\hline \multicolumn{6}{|c|}{$\mathrm{PF}$} \\
\hline$|\mathrm{V}|$ surface & 0.066 & 0.111 & 0.796 & 0.818 & 0.817 \\
\hline$|\mathrm{V}|$ bottom & 0.006 & 0.0061 & 0.101 & 0.106 & 0.106 \\
\hline$|\mathrm{V}|$ mean & 0.030 & 0.0331 & 0.366 & 0.387 & 0.386 \\
\hline
\end{tabular}

downwelling current. It is to be noted that at the 4 nearshore control points, the current in the entire water column has the same direction than the surface flow shown in Fig. 12. In addition, we can see that the velocities induced by the EDF runoff taken separately (i.e., without wind or tide effect) in these 4 areas would not influence substantially bottom currents, except for the $\mathrm{PB}$ area (Fig. 13c).

\subsection{Combined effects of strong wind and inflow}

Of course, the three mechanisms, analyzed in the preceding subchapters, occur simultaneously and are independent of each other: the tides alternate approximately every $6 \mathrm{~h}$; the wind is very often changing its direction and speed, while EDF runoff is seasonal. Now, on the basis on the results obtained in the previous subsections, we consider a situation in which two prevailing mechanisms (except tide) occur simultaneously and concurrently: SSE wind with a speed of $80 \mathrm{~km} \mathrm{~h}^{-1}$ and EDF runoff of $200 \mathrm{~m}^{3} \mathrm{~s}^{-1}$. For such a coupling, we could expect a larger velocity inside the eastern nearshore zones, like ZB. The influence of these two coupled forcings on the characteristic nearshore velocities (surface, bottom, average) is summarized in Table 1, which permits, in particular, a comparison between the results for SSE wind alone and coupled with large EDF runoff, respectively. We were expecting a co-current effect at PB. But, contrary to our expectation, the velocities are almost the same. That means that the co-current effect along the eastern shore is exactly balanced by the counter-current effect along the western shore. We observe almost the same balancing effect at the three other control areas, PA, PF and PM, for the same reasons. This means that the current is not simply the sum of the two contributions, confirming the strong nonlinearity of the system.

\section{Discussion and conclusions}

We have numerically investigated the nonlinear hydrodynamics induced by three main dynamical forcings (tide, wind and runoff) in Berre lagoon, a semi-closed hydrosystem which is subject to strong enough and frequent winds. This study was carried out as a contribution of a project of recolonization of protected seagrass (Zostera noltii) in some nearshore places in Berre lagoon.

The problem of recolonization of damaged seagrass is a very complex multiscale problem, which is the object of an always increasing number of studies, for both abiotic and biotic aspects, in many places in the world. Our contribution was concerning only one of the abiotic aspects (i.e., hydrodynamics) at the scale of the lagoon itself. That means that is was needed to make several assumptions; in particular, both free surface drag and bottom drag were assumed to be constant.

The use of the parallel version of MARS3D package permitted us to determine accurately the global influence of each mechanical forcing on the current structure in the whole lagoon and in the coastal areas. The circulation in the "Grand Etang" of Berre lagoon induced by the EDF inflow is a counterclockwise gyre. However, the pattern may be completely 
changed as a result of windforcing. For both main wind directions (NNW and SSE), the barotropic current is splitted into two separate gyres with coastal jets alongshore and windward. For strong NNW winds, the barotropic gyre is counterclockwise on the western side of the lagoon, and clockwise on the eastern side. For strong SSE winds, it is just the opposite.

The main result, which was never mentioned before in Berre lagoon literature, is the existence of these coastal jets, and the fact that the bottom velocity is varying nonmonotonically in these shallow water areas when approaching the shore. Bottom velocity of the order of $40 \mathrm{~cm} \mathrm{~s}^{-1}$, and faster, at a distance as small as $100 \mathrm{~m}$ from the shore, can be induced by a wind of the order of $80 \mathrm{~km} \mathrm{~h}^{-1}$.

Such coastal jets with high enough bottom velocity, which correspond to strong enough shear stress, can be expected to have an impact on the sediment composition, and thus, on the erosion resistance of the sediment (Ahmad et al., 2011). Indeed, as the living Zostera noltii are generally growing on mud-sand sediments, we can expect that the sediment composition was probably changed by a decreasing of mud concentration. Such changes in sediment properties, following the loss of seagrass, could be an important factor to explain the lack of recovery.

It is known that the dependency of mud-sand composition on the erosion resistance of bottom sediments is a very open problem. So, it would be pertinent, and very challenging, in view of future recovery programs to study very carefully this question of hydrodynamics-sediment interaction, at least in the case of strong bottom current.

Acknowledgements. This study was partly supported by the French Ministry of Higher Education and Research (French-Russian research-training programme), by the French Water Agency (AE-RMC-convention no. 2010-0042) and by the French Ministry of Foreign Affairs (ARCUS-Russia program). We also wish to thank reviewers for their pertinent remarks and questions.

Edited by: H. Kalisch

Reviewed by: two anonymous referees

\section{References}

Ahmad, M. F., Dong, P., Mamat, M., Wan Nik, W. B., and Mohd, M. H.: The critical shear stresses for sand and mud mixture, Appl. Math. Sci., 5, 2, 53-71, 2011.

Allen, J. S.: Coastal trapped waves in a stratified ocean, J. Phys. Oceanogr., 5, 300-325, 1975.

Blumberg, A. F. and Mellor, G. L.: A description of a TreeDimensional Coastal Ocean Circulation Model, Geophys. Fluid Dynam. Progr., Princeton Univ., Princeton, New Jersey, 1-16, 1986.

Bernard, G., Boudouresque, C. F., and Picon, Ph.: Long term changes in Zostera meadows in the Berre lagoon (Provence,
Mediterranean Sea), Estuar. Coast. Shelf Sci., 73, 617-629, 2007.

Cardoso, P. G., Raffaelli, D., and Pardal, M. A.: The impact of extreme weather events on the seagrass Zostera noltii and related Hydrobia ulvae population, Mar. Pollut. Bull., 56, 483-492, 2008.

Csanady, G. T.: Large-scale motion in the Great Lakes, J. Geophys. Res., 72, 4151-4161, 1967.

Csanady, G. T.: Baroclinic boundary currents and long edge-waves in basins with sloping shores, J. Phys. Oceanogr., 1, 92-104, 1971.

Fiandrino, A., Martin, Y., Got, P., Bonnefont, J. L., and Troussellier, M.: Bacterial contamination of Mediterranean coastal seawater as affected by riverine inputs: simulation approach applied to a shellfish breeding area (Thau lagoon, France), Water Res., 37, 1711-1722, 2003.

Fonseca, M. S., Kenworthy, W. J., and Courtney, F. X.: Development of planted seagrass beds in Tampa Bay, Florida, USA. I Plant components, Mar. Ecol. Prog. Ser., 132, 127-139, 1996.

Hunter, J. R. and Hearn, C. J.: Lateral and vertical variations in the wind-driven circulations in long, shallow lakes, J. Geophys. Res., 92, 13106-13114, 1987.

Koch, E. W. K., Sanford, L. P., and Chen, S.-N.: Waves in Seagrass Systems: Review and Technical Recommendations, USA Corps of Eng., report ERDC TR-06-15, 2006.

Koch, E. W., Barbier, E. B., Silliman, B. R., Reed, D. J., Perillo, G. M. E., Hacker, S. D., Granek, E. F., Primavera, J. H., Muthiga, N., Polasky, S., Halpern, B. S., Kennedy, Ch. J., Kappel, C. V., and Wolanski, E.: Non-linearity in ecosystem services: temporal and spatial variability in coastal protection, Front. Ecol. Environ., 7, 29-37, 2009.

Lazure, P. and Dumas, F.: An external-internal mode coupling for a 3-D hydrodynamical model at regional scale (MARS), Adv. Wat. Res., 31, 233-250, 2008.

Pickerell, C. H., Schott, S., and Wyllie-Echeverria, S.: BuoyDeployed Seeding: Demonstration of a new eelgrass (Zostera marina L.) planting method, Ecol. Eng., 25, 127-136, 2005.

Ramade, A.: Modalités d'ouverture du tunnel du Rove: approche des échanges qualité; internal report, Private communication, 1997.

Shafer, D. and Bergstrom, P.: An Introduction to a Special Issue on Large-Scale Submerged Aquatic Vegetation Restoration Research in the Chesapeake Bay: 2003-2008, Restor. Ecol., 18, 481-488, 2010.

Sogreah: BERRE - Etudes de premiere phase, Evaluation comparative des impacts maritimes des solutions B et T, 28 April 2003.

Van der Heide, T., van Nes, E. H., Geerling, G. W., Smolders, A. J. P., Bouma, T. J., and van Katwijk, M. M.: Positive feedbacks in seagrass ecosystems: Implications for success in conservation and restoration, Ecosystems, 10, 1311-1322, 2007.

Warner, R. F.: Environmental impacts of hydroelectric power and other anthropogenic developments on the hydro morphology and ecology of the durance channel and the Etang de Berre, southeast France, J. Environ. Manag., 104, 35-50, 2012.

Wilcox, D. C.: Turbulence Modelling for CFD, ISBN 1-928729-10$\mathrm{X}$, 2nd Ed., DCW Industries, Inc., 2004.

Wiseman, W. M. J. and Rouse, L. J.: A Coastal Jet in the Chukchi Sea. ARTIC, 33, 21-29, 1980. 